\title{
DEVELOPMENT OF THE MASDAN MOBILE APPLICATION AND WEB-BASED GIS INTERFACE FOR THE MONITORING AND MANAGEMENT OF THE MANILA BAY ENVIRONMENT
}

\author{
G. A. M. Narciso ${ }^{1 *}$, D. C. Fargas Jr. ${ }^{1}$, C. G. Candido $^{1}$, J. M. Medina ${ }^{1,2}$, M. L. P. Tinio ${ }^{1}$, A. C. Blanco ${ }^{1,2}$ \\ ${ }^{1}$ Training Center for Applied Geodesy and Photogrammetry, University of the Philippines Diliman, Quezon City 1101, Philippines \\ - (gmnarciso, dcfargas, jmmedina, acblanco)@up.edu.ph, (chriscandido93, ella.tinio)@gmail.com \\ ${ }^{2}$ Department of Geodetic Engineering, College of Engineering, University of the Philippines Diliman, Quezon City 1101, \\ Philippines
}

KEY WORDS: Mobile Application, WebGIS, Citizen Science, Environmental Issues, Manila Bay.

\begin{abstract}
:
This paper presents the development of MASDAN, an integrated platform consisting of a mobile application and a web-GIS interface for monitoring the Manila Bay environment. The MASDAN mobile application uses citizen science and Volunteered Geographic Information (VGI) to collect data on specific environmental issues. It also serves as an information, education, and communication (IEC) tool for its users. The MASDAN Monitoring Interface is a centralized citizen report assessment tool for local authorities and environmental agencies to validate and monitor environmental reports within their area of jurisdiction. These two components create a two-way flow of information between citizens and authorities, ensuring prompt and information-driven actions to environmental issues affecting the Manila Bay and linked environments.
\end{abstract}

\section{INTRODUCTION}

The Manila Bay watershed region covers a coastline length of $190 \mathrm{~km}$ and a surface area of 1,700 sq km (Jacinto et al., 1998; Jacinto et al, 2006). It is home to more than 32 million people (Philippine Statistics Authority, 2020). It is rich in natural resources making it a vital resource for many basic needs and livelihood of Filipinos in the region (Jacinto et al, 2006). Because of this, the bay has been exposed to extensive anthropogenic impacts resulting in environmental challenges such as problems due to solid wastes and water quality deterioration including hypoxia and harmful algal blooms (Sotto et al, 2014; Chang et al, 2009; Regmi, R.K., 2018). In the past four decades, declining water quality in the area has been indicated by the occurrence of hypoxia and increased microbial activity due to the eutrophication and chemical pollution caused by the increased urban activity (Chang et al, 2009). Aside from this, solid waste problems in nearby areas also contribute to higher risks of flooding especially for areas near the rivers connected to the Manila Bay (Regmi, R.K., 2018; Jacinto et al., 2006).

The challenges mentioned are proof that there is a need to effectively rehabilitate Manila Bay, however, while there already have been efforts initiated by the government, the lack of participation from the public often pose a challenge to the different initiatives. The involvement of the public has been crucial to the success of such projects as it has been perceived to help in attaining positive change, therefore the lack of public involvement often affects the effectiveness of the initiatives (Balgos, 2005; Ruiz, 2019).

Aside from the lack of public participation, implementation of initiatives and existing mechanisms seem to be lacking which has been the case for the existing environmental laws in the country, that while a number of laws can be applied to the Manila Bay, the lack of political will and problems caused by conflicts of jurisdiction instead served as obstacles to effectively enforcing the laws (Jacinto et al., 2006).
This problem serves as the motivation of this study in which digital technologies were explored to develop a system allowing a two-way flow of information between the public and authorities, ensuring prompt and information-driven actions to environmental issues affecting the Manila Bay.

This paper presents the development of MASDAN, an integrated platform consisting of a citizen science mobile application and a centralized citizen report assessment WebGIS for monitoring the Manila Bay environment. This system aims to provide a solution to the monitoring and assessment of the Manila bay through a Geographic Citizen Science approach implemented through the mobile application and the application of WebGIS.

\section{RESEARCH BACKGROUND}

\subsection{Citizen Science}

Citizen Science is a technique or a model that is now commonly used in scientific research projects in which it engages the citizens to participate in the scientific process mainly as field assistants or "citizen scientists" who are volunteers for the collection of significant data over a large study area or a long duration of time (Newman et al, 2010; Silvertown, 2009; Bonney et al, 2009). This has been a significant approach to communitybased science with different levels of involvement as it addresses not only the problem of data acquisition but also improves the capability of the scientific project to disseminate information (Newman et al, 2010). Moreover, this model also improves the scientific process as it promotes communication not just among the involved citizens but also between the professional scientists and the citizens therefore resulting in better understanding the collected data (Newman et al, 2010; Chmielewski et al, 2017).

Various scientific projects have been successful due to their adoption of the citizen science model such as the projects of the Cornell Laboratory of Ornithology in which, aside from success

\footnotetext{
${ }^{*}$ Corresponding author
} 
in the data collection which yielded significant results helping understand and answer the different research questions, it was also found that the approach resulted in better educational outcomes for the engaging citizens (Bonney et al, 2009).

With the development of digital technology, the potential of citizen science has significantly increased due to the more effective dissemination of information and the availability of tools for communication and standardized data collection. WebGIS applications have been one of the support tools adopted for citizen science projects on ecology and urban studies (Chmielewski et al., 2017; Bell et al., 2008).

\subsection{Volunteered Geographic Information}

Volunteered Geographic Information (VGI) describes a phenomenon in a GIS community in which there is a widespread engagement of citizens to voluntarily collect data to produce geographic information (De Reyna, M. \& Simoes, J., 2016; Goodchild, M.F., \& Li, L., 2012). The overlap between VGI and Citizen Science produces Geographical Citizen Science which focuses on scientific projects on environmental issues such as pollution, habitat and biodiversity (Reyna, M. \& Simoes, J., 2016)

With the application of VGI in Citizen science projects, there had been significant changes in the geographic information, in terms of amount and availability (Flanagin, A.J., \& Metzger, M.J., 2008). Through VGI and the development of communication, the internet and the capability of technological devices capable for data collection, geographic data has been significantly enhanced however, there are caveats with regards the quality, reliability and the value of the data (Flanagin, A.J., \& Metzger, M.J., 2008; De Reyna, M. \& Simoes, J., 2016). For citizen science projects utilizing the VGI approach, quality assurance mechanisms must therefore be considered and developed.

\subsection{Web-GIS}

Technological advancements such as the internet and the integration of location devices in mobiles phones brought about the development of Web GIS, a category of GIS that has been significantly used for Geographic Citizen Science projects due to its capabilities which include the provision of near real-time visual interaction with data in the form of maps and secondly, because of it being deployed in the web, geospatial data can be widely accessible by its users (De Reyna, M. \& Simoes, J., 2016; Alasheikh et al. 2002). The availability of this technology really improved the efficiency of communication and the evaluation process of Geospatial data (Alasheikh et al., 2002).

Web GIS is composed of two main components, the web server which comprised of the database where geospatial data and maps are stored through some set of routes for requesting and storing data, and secondly, the interface of the Web GIS which is accessed by the clients or the users to actually visually interact with the geospatial data (De Reyna, M. \& Simoes, J., 2016).

\section{MATERIALS AND METHODS}

\subsection{Study Site}

The area of study is the coastal system of Manila Bay and its watershed, one of the busiest bays in the Seas of Southeast Asia and a marine pollution hotspot (Sta. Maria, et al, 2009).
It is bounded by Bataan Province to the west, by Bulacan Province to the north, by the National Capital Region to the east, and by the province of Cavite to the south. Its river basins also extend to the provinces of Pampanga, Rizal and Laguna - all of which are part of the Manila Bay Watershed Region (outlined in Figure 1).
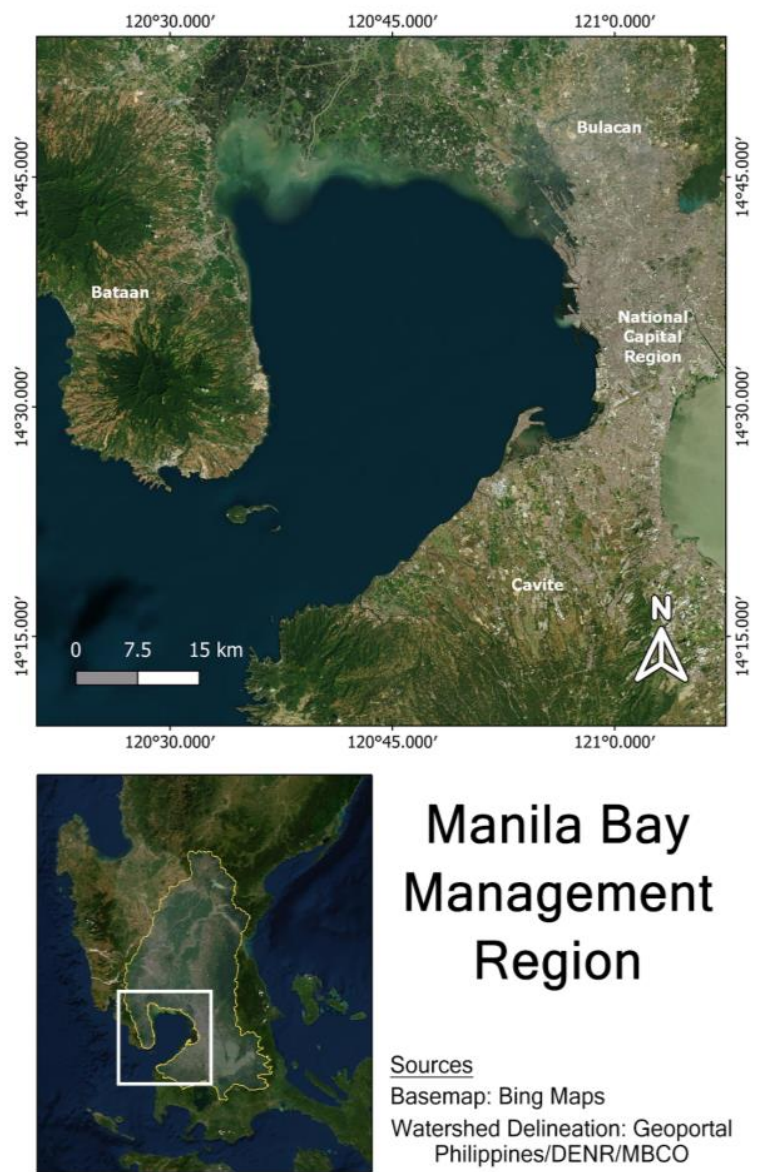

\section{Manila Bay Management Region}

Sources

Basemap: Bing Maps

Watershed Delineation: Geoporta Philippines/DENR/MBCO

Figure 1. Manila Bay Region

\subsection{Participatory System Design}

In designing the mobile application, certain key aspects have to be considered to characterize its effectiveness. These include usefulness, quality, adaptability, availability, conveyability, effectiveness, practicality, ease of use and responsiveness. To meet these criteria, a user survey was conducted in order to identify components which were deemed important to maximize functionality and improve the user experience.

Four sectors were targeted for the user survey, namely, Academe and Research, Local Government Units (LGUs), National Government Agencies (NGA), and Private Sector. The survey was designed such that it reflects the user stories form, which gathers data based on perceived user gains or benefits from using the app. To provide context on the answers, the role of the respondent in his/her institution/office/agency was asked, followed by a question on how he/she thought the app can be helpful to him/her based on that role.

A profile of the respondents of the user survey was formulated based on their age bracket, location, job sector, operating system of mobile device, and mobile signal strength and stability. 
Respondents were also asked what environmental concerns should be included in the mobile application reporting activity.

\subsection{Component Platforms}

The system consists of two component platforms: the MASDAN Mobile Application to be used by the general public to collect data and submit reports on certain environmental concerns; and the MASDAN Monitoring Interface (MMI) to be used by local authorities and environmental monitoring agencies to review and assess incoming data.
The MASDAN Mobile Application serves as the main component for Geographic Citizen science which provides a platform for ordinary citizens to engage in the environment monitoring and assessment. The mobile application provides for the data acquisition of reports on environmental incidence within or nearby the study area, which is the Manila Bay. The application systematizes the acquisition of data which results in the collection of formatted reports which can be better used for research and analysis. The report is composed of a captured image, as proof for the incident, report information based on a designed questionnaire, timestamp and the coordinates of the report.

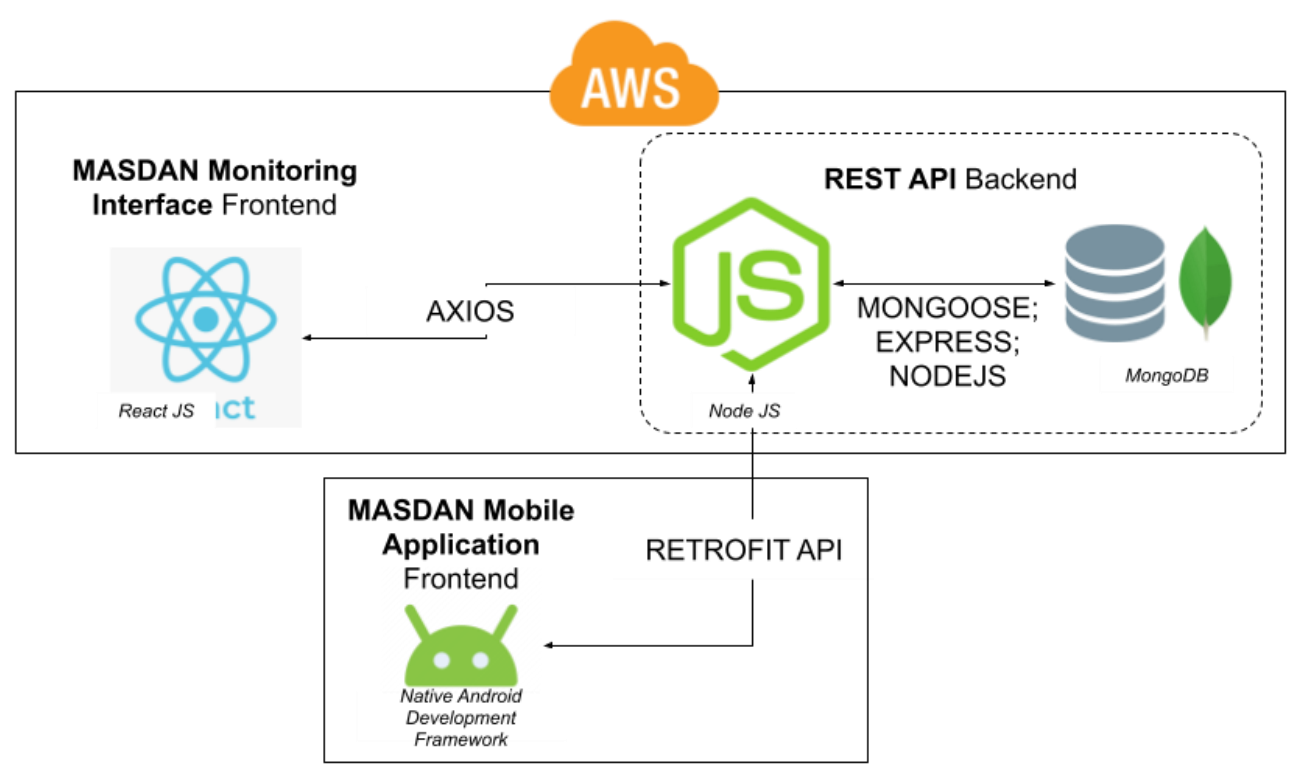

Figure 2. MASDAN Digital System Architecture

The monitoring interface, on the other hand, is for the members of different agencies and institutions responsible for responding to reported environmental issues within their jurisdiction. This interface provides a system for accessing and verifying the reports. Feedback system is also implemented in this component, creating a two-way flow of information between the citizens who submitted the report through the mobile application.

\subsection{Development Frameworks}

The user interface of the MASDAN mobile application was developed using the Native Android development framework while the monitoring interface follows the React JS framework. As for the data storage, MongoDB, a NoSQL type of database was utilized as the main data storage which was connected to the two component platforms through a Representational State Transfer (REST) API. This API was developed using the Node JS and Express JS development frameworks which allowed the communication of data between the user interfaces and the database.

From the mobile application user interface, Retrofit was used for sending HTTP requests to and receiving responses from the REST API. The monitoring interface on the other hand, relied on the use of Axios, a promise-based HTTP client for Node JS for initiating HTTP requests from the frontend.

Aside from these frameworks, several spatial analysis APIs were also utilized for the GIS aspect of the system. For the geotagging of reports, aside from the Google maps which can be used to obtain the coordinates of the report from the map, the GNSS receiver of the android smartphone was utilized as well for measuring precise position. Additionally, Mapbox was used for the visualization of verified reports in the map component of the mobile application. For the monitoring interface, Leaflet JS was the main API used for the visualization of data on a map, and segregation of access to reports depending on the area of interest or jurisdiction of the user defined by a GeoJSON file.

\subsection{Users}

There are different types of users of the system, there are the general users of the mobile application who serve as the "Citizen Scientists" of the project and there are also the users of the monitoring interface who are classified into three categories, the administrators, organization administrators, and users.

The general users are mainly limited to using the mobile application. Their accounts are not applicable for the monitoring interface, so a user of both components has to create a separate account for each.

As for the users of the monitoring interface, there is a need to define different use cases of the application with regard to the level of accessibility to the reports. The highest classification of users is the Administrator. This is for users who are responsible for the maintenance of the system and management of the users' accounts. Administrators have the capability to create, approve, reset and delete user accounts. Aside from user accounts, Organization accounts can also be created by the administrators. 
Organization accounts segregate access to reports depending on their jurisdiction. By creating an organization account, the administrator can define the organization's access level based on its administrative and geographic jurisdiction. These accounts do not function like user accounts, but rather as user classes to control access to the system by the different groups of users.

Organization administrators and users belong to an organization account. Unlike the system administrators, organization administrators can only create, reset, and delete accounts under their organization. They cannot create other organization accounts. As for the users, their capability is limited to the verification of reports which depend on the level of access of their organization.

\begin{tabular}{|l|c|c|c|}
\hline & $\begin{array}{c}\text { Create } \\
\text { Orgs/ } \\
\text { Admins }\end{array}$ & $\begin{array}{c}\text { Create } \\
\text { Users } \\
\text { for an } \\
\text { Org }\end{array}$ & $\begin{array}{c}\text { View/ Validate } \\
\text { Report }\end{array}$ \\
\hline Administrator & $\checkmark$ & $\checkmark$ & $\checkmark$ \\
\hline $\begin{array}{l}\text { Organization } \\
\text { Administrator }\end{array}$ & $x$ & $\checkmark$ & $\checkmark$ \\
\hline Users & $x$ & $x$ & $\begin{array}{c}\text { Depend on } \\
\text { Level of Access }\end{array}$ \\
\hline
\end{tabular}

Table 1. User roles in the MASDAN Monitoring Interface

\subsection{Object Models}

An object model defines the structure of an object through its attributes. Each attribute is represented by a key-value pair and may also be used to define inheritance and relationships with other objects.

For efficient handling of datasets, the backend developers have defined the following object models for the various datasets including the Users which is further divided into two classes, the Mobile Application users and the monitoring interface users, Organization Accounts, Reports, Report Log and for the image attributed to a report.

While MongoDB databases can be used to store datasets without schema or structure, following a document-based data handling, categorizing datasets as mentioned above systematizes the retrieval and input of data to the database. This in turn results in a more efficient and secured handling of data.

Figure 3 shows an ER diagram that exhibits the connection between the different object models for this system.

Two separate user object models are used in the MASDAN system to distinctly identify users of the mobile application and the monitoring interface. These object models are significant to the tracking and monitoring of input of reports to the system. As for the reports, the report description and its corresponding image or photo documentation have been separated to prevent lag times when loading information to the browser or the application. Users sending reports and users validating reports are linked through the report descriptions, photo attachments, and status of the report/action items.

Finally, the report logs are datasets containing changesets to the status of the reports implemented by the Monitoring Interface users in the process of validating data. With regard to the validation capabilities of a Monitoring Interface user, it will be linked to the user's organization account.

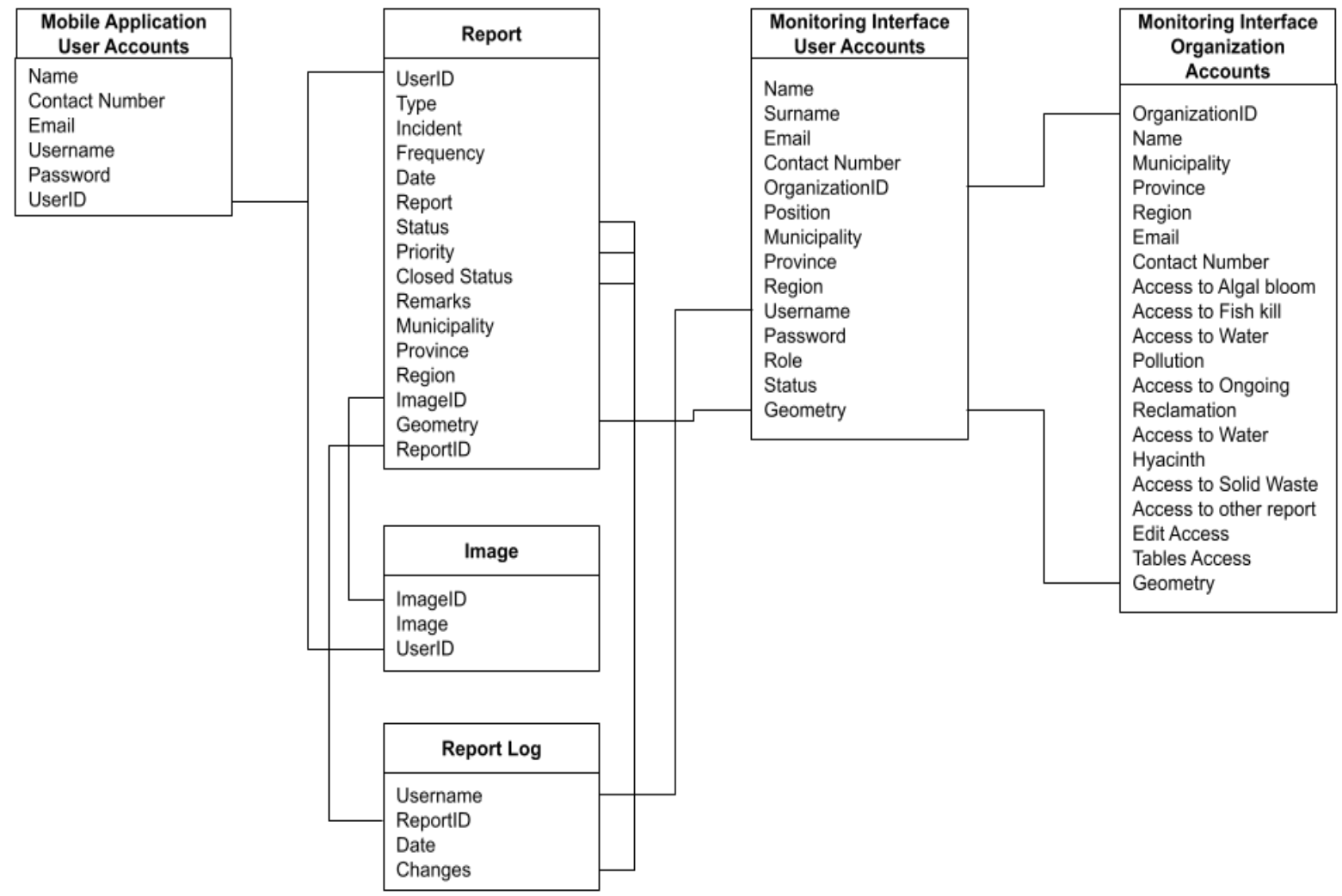

Figure 3. Data objects ER diagram 


\subsection{Data Flow and Quality Assurance Process}

The core data of the system are the reports submitted by the general users or the "citizen scientists" through the mobile application. A report is composed of a report description, a photo documentation which serves as supporting proof to the report, a timestamp, and the coordinates of the report. Once a report is submitted, it is automatically stored in the database. This can be accessed by the MMI users from the local authorities and environment monitoring agencies. Reports are geospatially segregated by their coordinates using spatial analysis to match with the geographic jurisdiction of the concerned agencies. Once matched, users of the MMI obtain access to the reports within their jurisdiction for validation and assessment.

The quality assurance process is composed of four actions. Reports are tagged as valid or false positives based on the provided description and image attachment. By default, the status of the report is set to unverified. Second, users/validators set the priority levels of the report to low, medium or high. Remarks are then added to the report whether there are specific actions needed to be done. Lastly, a report is permanently closed after it has been addressed by the local authority or the agency responsible for the reported environmental incident.

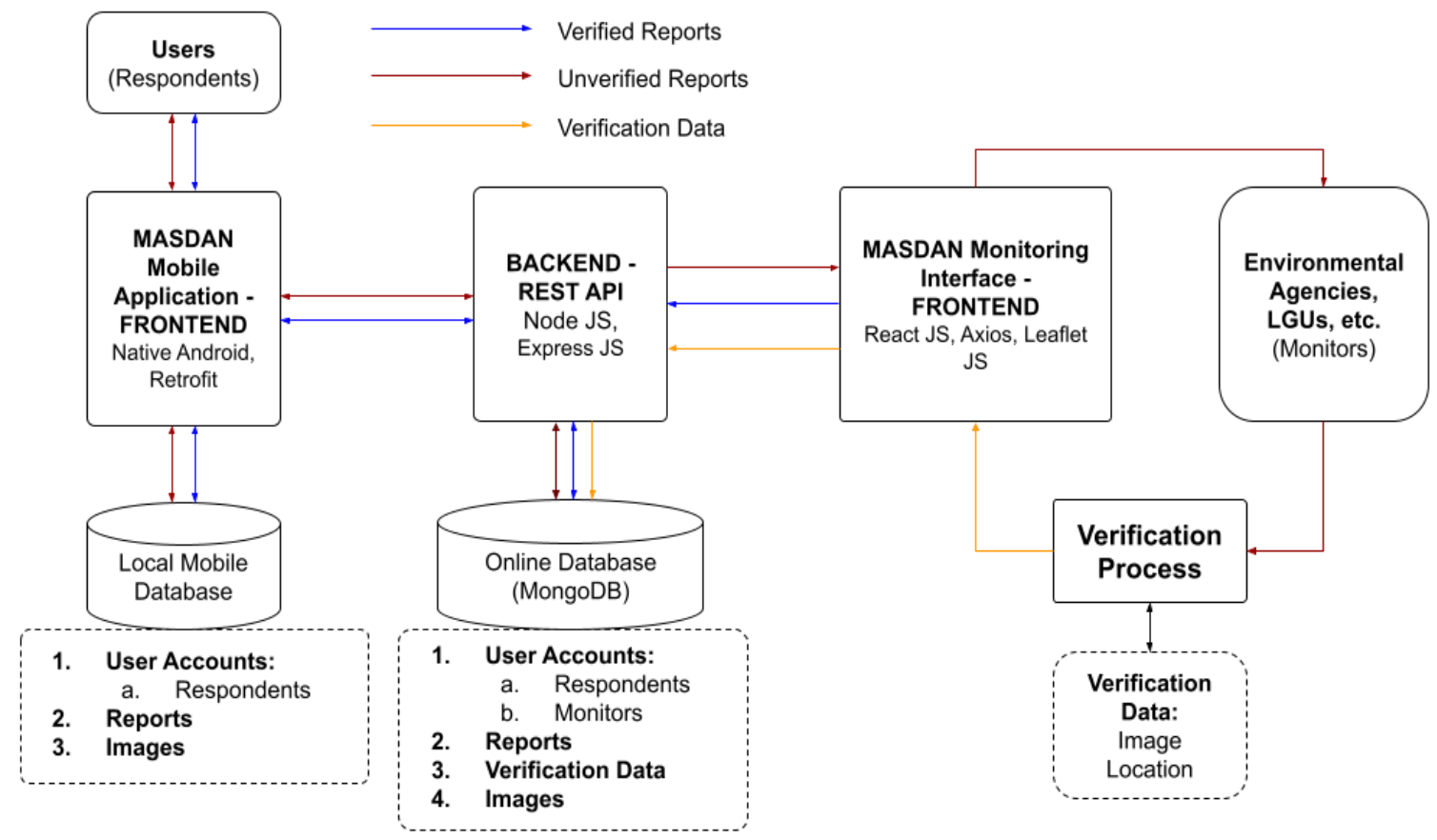

Figure 4. Flow of data

\section{RESULTS AND DISCUSSION}

\subsection{Participatory Survey Results}

A total of 62 survey respondents participated in the online survey with young adults making up the majority ( $35 \% 18-25$ years old and 39\% 26-35 years old). Most of them came from the Private Sector $(31 \%)$, followed by the Academe and Research Sector (25\%), Local Government Units (22\%), and Non-Government Organizations (21\%). Out of all the respondents, 57\% lived and/or worked in the National Capital Region (NCR). Other respondents were from the Manila Bay watershed provinces of Bataan, Bulacan, Cavite, Laguna, Pampanga, and Rizal. The remaining six percent $(6 \%)$ came from provinces outside the Manila Bay watershed.

The mobile service sensing survey revealed that $74 \%$ of the respondents used Android devices only, while 15\% used both Android and iOS devices. Regardless of other technical factors and considerations, building and developing a mobile application using Android OS is the more feasible option since most of the respondents are Android users. This also confirms the dominance of Android OS in the current market share of mobile operating systems in the Philippines. The development of an iOS version of the application may still be considered for the few $(11 \%)$ users who solely use an iOS device.

Sixty-five percent $(65 \%)$ of the respondents reported a moderate mobile signal reception, while $26 \%$ reported a strong signal with varying stabilities. This presumes that mobile signal represents data service (i.e., mobile internet) rather than Wi-Fi connection in their home or workplace. The option to store reports for later submission should be investigated to include places with poor and/or intermittent cell coverage.

Results of the survey suggest that the mobile application may be useful in three key areas namely; decision and policy making, information and education campaign (IEC), and research and development. Many of the respondents proposed the features and functionalities of the monitoring systems be utilized not only by LGUs and NGAs, but also by local communities. Aside from the monitoring system, some respondents wished to have the mobile application be used as a tool for teaching and educating citizens, particularly the youth, about Manila Bay and the environment in general and to urge them to participate actively in conservation and management activities. respondents saw the app as a tool for data collection in studies involving Manila Bay and its watershed. Table 2 shows the summary of features and capabilities with its corresponding priority. 


\begin{tabular}{|c|c|}
\hline Feature/Capability & Priority \\
\hline User registration & High \\
\hline Geotagging & High \\
\hline Submission of photo documentation & High \\
\hline $\begin{array}{l}\text { Submission of basic information such as } \\
\text { timestamp, location, and description of report }\end{array}$ & High \\
\hline Feedback mechanism & High \\
\hline About page & High \\
\hline User profile/account & Moderate \\
\hline User report summary & Moderate \\
\hline "How To" page & Moderate \\
\hline Summary statistics of reports & Moderate \\
\hline Reward/point system & Moderate \\
\hline About Manila Bay & Moderate \\
\hline Resources page & Moderate \\
\hline Confidentiality clause & Moderate \\
\hline News/updates page & Low \\
\hline Map interface & Low \\
\hline $\begin{array}{l}\text { Capable of sharing information on social media } \\
\text { platforms }\end{array}$ & Low \\
\hline $\begin{array}{l}\text { Scoring system for LGUs in terms of } \\
\text { implementation of solid waste management } \\
\text { programs }\end{array}$ & Low \\
\hline $\begin{array}{l}\text { Self-monitoring capability for industries } \\
\text { discharging wastewater into the bay }\end{array}$ & Low \\
\hline Open source data & Low \\
\hline
\end{tabular}

Table 2. Summary of suggested mobile application features and capabilities
Respondents suggested the following environmental issues to be included in the mobile application: wastewater discharge, algal bloom, fish kill, illegal solid waste disposal, illegal fishing activities, encroachment in water ways, and illegal reclamation. According to studies, Manila Bay has a wide range of environmental issues that need to be addressed from land-based and sea-based sources of pollution, harmful algal blooms, overexploitation of fishery resources, and habitat degradation. The suggested environmental concerns from the respondents coincides with the environmental issues that the Manila Bay is currently facing. From the suggested concerns, chosen environmental issues were included in the monitoring system: algal bloom, fish kill, water pollution, ongoing reclamation, water hyacinth, and solid waste.

\subsection{MASDAN Mobile Application}

The MASDAN Mobile Application follows a geographic citizen science framework to promote community engagement in monitoring of environmental issues in the Manila Bay watershed. The Android mobile application consists of four modules:

User Profile Module: This contains the user profile which contains information such as name, username, and email address), as well as the number of reports sent, and accumulated points and badges.

Report Module: The user answers a set of questions regarding a specific environmental concern and attach a photo documentation as evidence. This uses mobile GPS to geotag the report.

Map Module: The user sees the location of reports they and other users submitted on a map. Each type of reported environmental concern is represented by a unique point marker.

IEC Module: This contains information about the Manila Bay environment, relevant environmental laws and policies, and rehabilitation efforts.
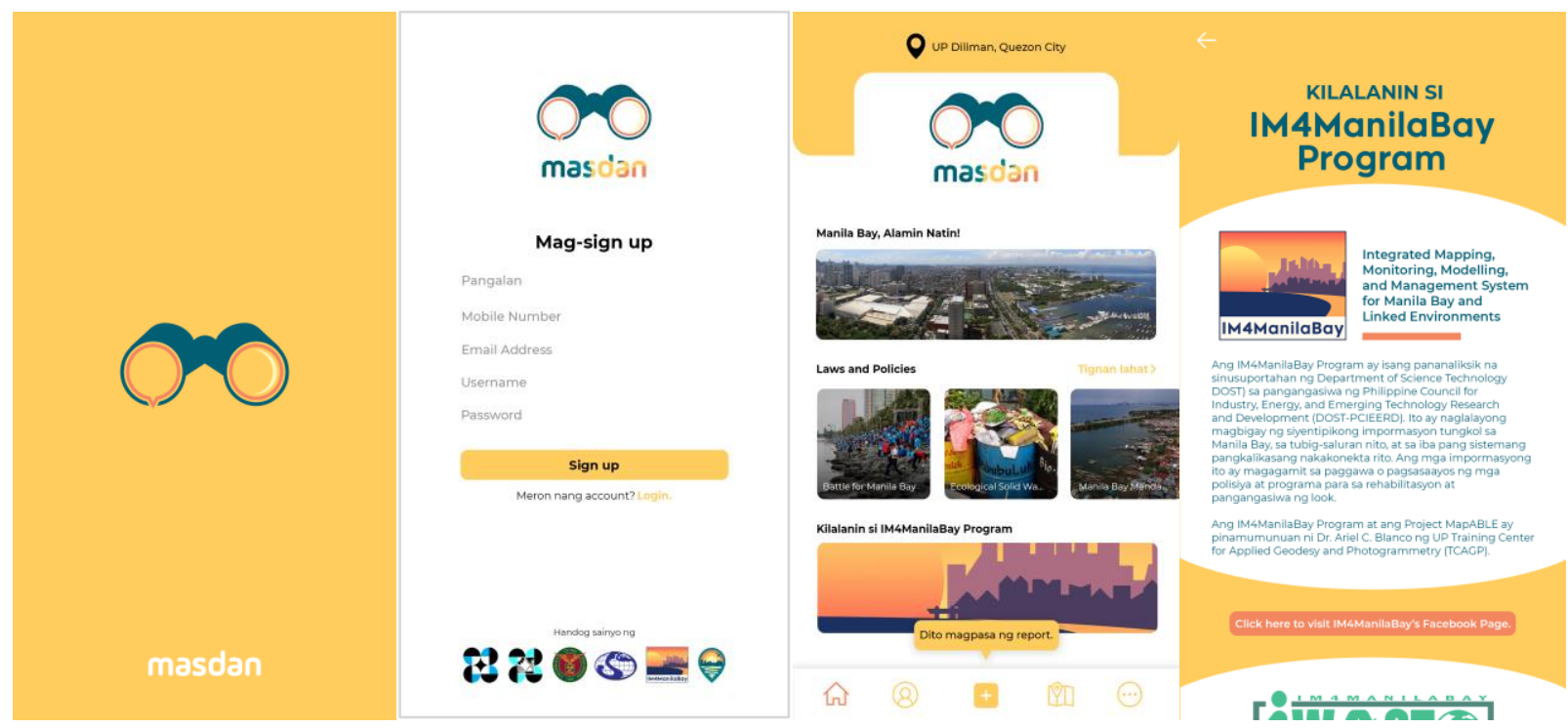

Figure 5. MASDAN Mobile Application user interface 


\subsection{MASDAN Monitoring Interface}

The MASDAN Monitoring Interface (MMI) allows local authorities and environmental agencies to: (1) view submitted reports in real-time; (2) provide prompt assessment and feedback; and (3) visualize the location of reported concerns and generate summary statistics reports. The web-based platform consists of four modules:

Dashboard Module: The user sees a list of all reports reported through the mobile app and their locations plotted on a map. Reports may be filtered by type, status, date, or priority level.

Report Module: The user can provide feedback and an assessment on a report. Other details including the photo documentation of the report are visible to help in the assessment and validation.

Table Module: The user sees a summary statistic table of reports per incident type, priority level, and status. Reports may also be generated and exported as a CSV file through the module.

Registration Module: Agency/department supervisors may add new users and organizations to the monitoring interface. User and organization accounts are given specific levels of access and capabilities based on the geographic and administrative jurisdiction of their offices or agencies.

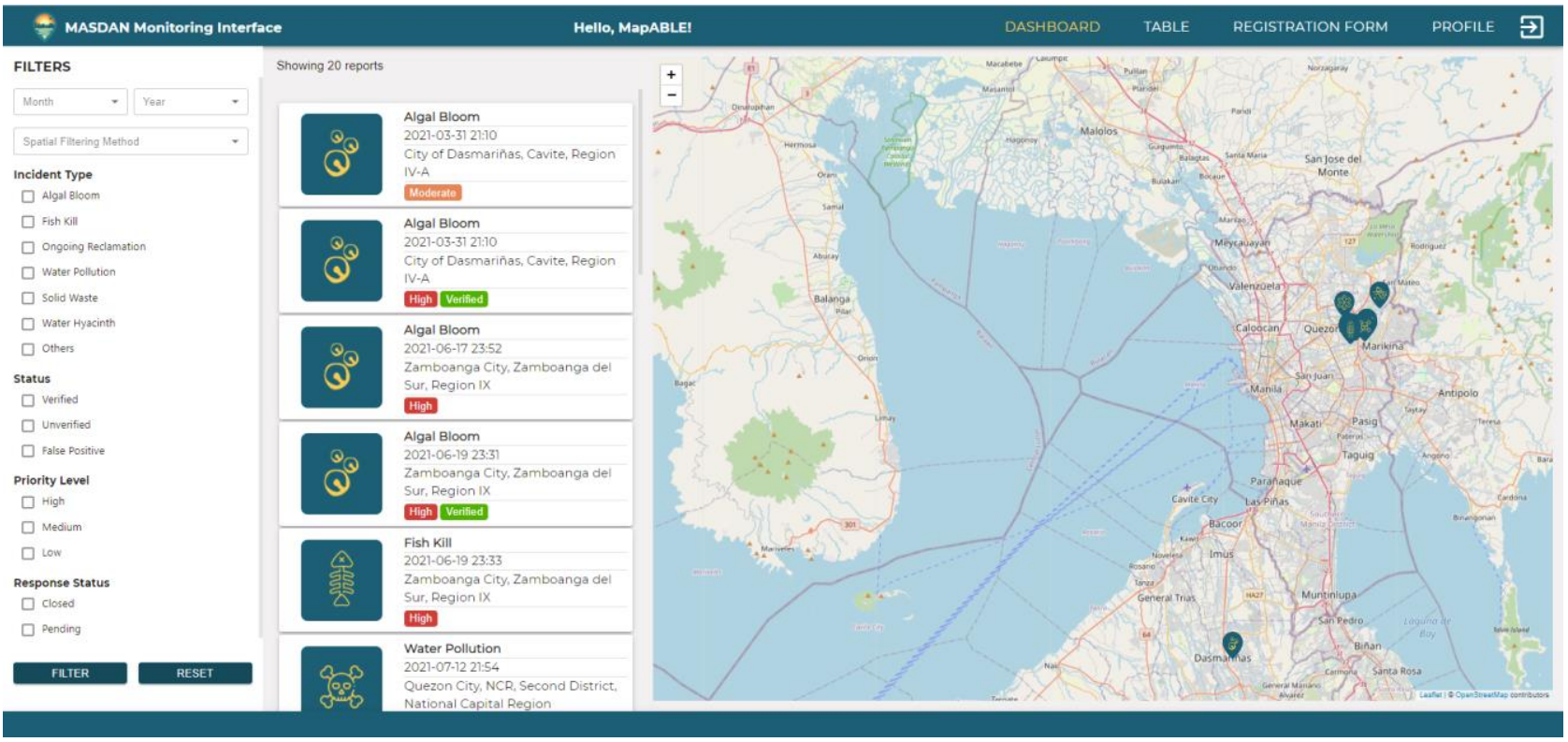

Figure 6. MASDAN Monitoring Interface

The MASDAN mobile application was successfully created and deployed to the Google Play Store. An example of its interface can be seen in Figure 5. To encourage citizen participation and sustainability, gamification of the application was performed through leaderboards and badges. Report submissions include an image and a geotag (latitude and longitude), with possible further support for multiple images or videos.

The MASDAN Monitoring Interface was successfully created and deployed to the internet for use by various institutions/organizations. An example of its interface can be seen in Figure 6. Coordination with local government units and national government agencies is important to properly delineate jurisdictions and identify different user roles for validation of reports.

\section{CONCLUSION AND RECOMMENDATIONS}

A mobile application and monitoring interface were created to systematically collect data using Volunteered Geographic Information and Citizen Science. This creates a two-way communication between the citizens, local authorities, and environment monitoring agencies and establishes a mechanism to ensure quality of data. The system addresses the jurisdictional conflicts among local authorities and environmental monitoring agencies by assigning levels of access to each organization as well as viewing/validating roles. Aside from data collection and validation, the mobile application can also be used for information dissemination through the IEC module.

To further improve the system, recommendations include the Gamification of the system, development of a cross-platform version and the implementation of further pilot study and test runs.

The Gamification of the system will help improve its sustainability in terms of its use as well as increase mobile user engagement so as to ensure continuity not just with regards the collection of data but also the engagement between the citizens and the authorities.

The development of a cross-platform version of the mobile application is also recommended in order to expand the target users of the system.

Lastly, the implementation of a pilot study and test runs of the system will allow inclusivity in the development of the system involving the users and the different stakeholders. This will further ensure that the needs of the users are addressed and that the user experience and the interface will conform to the interests of the users, the partners and significant stakeholders. 


\section{ACKNOWLEDGEMENTS}

This research was done as part of the Development of Integrated Mapping, Monitoring, and Analytical Network System for Manila Bay and Linked Environments (MapABLE) Project. The Project was implemented by the University of the Philippines Training Center for Applied Geodesy and Photogrammetry (TCAGP), through the support of the Department of Science and Technology (DOST) of the Republic of the Philippines and the Philippine Council for Industry, Energy, and Emerging Technology Research and Development (PCIEERD). This research also acknowledges the participation of all the respondents of the user survey and beta-testers of the mobile application and monitoring interface.

\section{REFERENCES}

Alesheikh, A. A., Helali, H., \& Behroz, H. A. (2002, July). Web GIS: technologies and its applications. In Symposium on geospatial theory, processing and applications (Vol. 15).'

Balgos, M. C. (2005). Integrated coastal management and marine protected areas in the Philippines: concurrent developments. Ocean \& coastal management, 48(11-12), 972995

Bell, S., Marzano, M., Cent, J., Kobierska, H., Podjed, D., Vandzinskaite, D., ... Mursic, R.

(2008). What counts? Volunteers and their organisations in the recording and monitoring of biodiversity. Biodiversity and Conservation, 17, 3443-3454. https://doi.org/ 10.1007/s10531-008-9357-9.

Bonney, R., Cooper, C. B., Dickinson, J., Kelling, S., Phillips, T., Rosenberg, K. V., \& Shirk, J. (2009). Citizen science: a developing tool for expanding science knowledge and scientific literacy. BioScience, 59(11), 977-984.

Chang, K. H., Amano, A., Miller, T. W., Isobe, T., Maneja, R., Siringan, F. P., ... \& Nakano, S. I. (2009). Pollution study in Manila Bay: eutrophication and its impact on plankton community. Interdisciplinary studies on environmental chemistry-environmental research in Asia. Tokyo: Terrapub, 261-267.

Chmielewski, S., Samulowska, M., Lupa, M., Lee, D. J., \& Zagajewski, B. (2018). Citizen science and WebGIS for outdoor advertisement visual pollution assessment. Comput. Environ. Urban Syst., 67, 97-109.

de Reyna, M. A., \& Simoes, J. (2016). Empowering citizen science through free and open source GIS. Open Geospatial Data, Software and Standards, 1(1), 1-12.
Flanagin, A. J., \& Metzger, M. J. (2008). The credibility of volunteered geographic information. GeoJournal, 72(3-4), 137 148.

Goodchild, M. F., \& Li, L. (2012). Assuring the quality of volunteered geographic information. Spatial statistics, 1, 110 120 .

Jacinto, G. S. (1998). N and P budget of Manila Bay, Philippines. LOICS website.

Jacinto, G. S., Azanza, R. V., Velasquez, I. B., \& Siringan, F. P. (2006). Manila Bay: environmental challenges and opportunities. In The environment in Asia Pacific harbours (pp. 309-328). Springer, Dordrecht.

Jacinto, G. S., Velasquez, I. B., Villanoy, C. L., \& Siringan, F. B. (2006). Biophysical environment of Manila Bay - then and now. In The Environment in Asia Pacific Harbours (pp. 293307). Springer, Dordrecht.

Newman, G., Zimmerman, D., Crall, A., Laituri, M., Graham, J., \& Stapel, L. (2010). User-friendly web mapping: lessons from a citizen science website. International Journal of Geographical Information Science, 24(12), 1851-1869.

Philippine Statistics Authority. (2021, July 7). 2020 Census of Population and Housing. Philippine Statistics Authority. Retrieved September 11, 2021, from https://psa.gov.ph/content/2020-census-population-andhousing-2020-cph-population-counts-declared-officialpresident.

Regmi, R. K. (2017). Urbanization AND related environmental issues of metro manila. Journal of Advanced College of Engineering and Management, 3, 79-92.

Ruiz, E. de V. (2019, April 2). Public participation key to success in Manila Bay rehab - Denr. Manila Bulletin. October 12, 2021, from https://mb.com.ph/2019/04/02/publicparticipation-key-to-success-in-manila-bay-rehab-denr/.

Silvertown, J., 2009. A new dawn for citizen science. Trends in Ecology \& Evolution, 24, 467-471.

Sotto, L. P. A., Jacinto, G. S., \& Villanoy, C. L. (2014). Spatiotemporal variability of hypoxia and eutrophication in Manila Bay, Philippines during the northeast and southwest monsoons. Marine pollution bulletin, 85(2), 446-454.

Sta. Maria, E. J., Siringan, F. P., Bulos, A. d., \& Sombrito, E Z. (2009). Estimating sediment accumulation rates in Manila Bay, a marine pollution hot spot in the Seas of East Asia. Marine Pollution Bulletin, 59(4-7), 164-174. doi:https://doi.org/10.1016/j.marpolbul.2009.04.017 